\title{
Lärares yrkesetiska dilemman och den ökande juridifieringen i Sverige
}

\section{Gunnel Colnerud}

Linköpings Universitet Sverige

gunnel.colnerud@liu.se

Följande artikel under temat "Etikbølgen i yrkesutdanning og praksis" beskriver och diskuterar etik och juridik i läraryrket med utgångspunkt $i$ det dilemma som lärare själva anser vara ett av de svåraste enligt två svenska empiriska studier - att ingripa mot en kollega som handlar etiskt klandervärt mot elever. Artikeln diskuterar vidare den dygdetiska kritik mot regeletik som förekom vid tillkomsten av de etiska principerna. Vidare pekar den på de problem som följer av att lärarna är föremål för en tilltagande juridifiering. En våg, en bølge, kan beröra endast ytan som en krusning eller vara en djupgående och energirik rörelse. För att använda den aktuella metaforen på mitt studieobjekt skulle jag vilja påstå att diskussionen av lärares yrkesetik och medvetenheten om svenska lärares etiska riktlinjer utvecklades till en våg av endast blygsam storlek. I dagsläget (2014) har den ersatts av en juridisk våg med stor kraft.

Nyckelord: etik i läraryrket, etiska dilemman, juridifiering av lärarpraktiken

\begin{abstract}
English summary: Teachers' ethical dilemmas and the juridification of the Swedish school

In this article, ethics and law in the teaching profession are described and discussed, starting with the ethical dilemma that teachers point to as the most difficult, according to referred empirical studies - intervention when a colleague acts in an ethically incorrect way towards students. Furthermore the author discusses the critique coming from virtue ethics in relation to ethical principles and shows that even Aristotle suggests ethical principles under certain circumstances. Swedish teachers' ethical principles had very little time to be achieved before an increasing juridification of teaching took place. This phenomenon is discussed in terms of professional autonomy and professional judgement.
\end{abstract}

Keywords: ethics in teaching profession, ethical dilemmas, juridification of teaching practice 


\section{Bakgrund}

Lärares moraliska ansvar för att eleverna både lär sig det de behöver och för att de samtidigt blir behandlade på ett sätt som är bra för dem var i Sverige sällan diskuterat som en kollektiv professionsfråga före 1990-talet. Den internationella forskningen om moraliska dimensioner av läraryrket, exempelvis Tom (1984), Goodlad (1990) och Bergem (1993), inspirerade då den svenska diskussionen om behovet av en gemensam yrkesetik. Det var framförallt den ojämlika, asymmetriska relationen mellan lärare och elev som betonades, liksom dess konsekvenser för lärarens ansvar för elevens välbefinnande. Man kan se det som en synvända: från synsättet att lärare har rätt till eleverna, i betydelsen att de förfogar över eleverna, till att eleverna har rättigheter, framför allt rätten att bli väl behandlade. Den rätten följer av att de är tvingade att vistas i skolan. Bergem (1993) uttryckte detta nya synsätt på lärares förhållande till eleverna i sin avhandlingstitel, vilken löd: "Tjener, aldri herre". Diskussionen fyllde ett tomrum för såväl lärare som allmänhet, som hade känt moraliska invändningar mot att lärare kunde utöva sitt yrke efter eget, ibland dåliga, omdöme utan att kritiseras. Det saknades gemensamma kriterier för vad som var ett gott eller dåligt sätt att utöva läraryrket. Inte ens en lägsta gräns för vad som var acceptabelt beteende kunde anges. Detta blev tydligt i den första svenska empiriska studie inom området som genomfördes under första hälften av 1990-talet (Colnerud 1995).

\section{Kollegors etiska övertramp}

Den studie som bidrar med empiriskt underlag till denna artikel genomfördes med hjälp av Critical-Incident-Teknik (CI) vilket innebär att lärare ombads beskriva etiska problem och dilemman, händelser som de ansåg ha varit svåra att hantera ur moralisk/etisk synpunkt. CI är en metod som är lämplig när man undersöker händelser som uppträder diskontinuerligt, exempelvis situationer som väcker individens uppmärksamhet för att de är särskilt svåra att finna en lösning på (bl.a. Flanagan 1954; Eriksson \& Larsson 1974; Colnerud 1995, 1997, 2014a).

Ett av de mest frekventa etiska problemen utgjordes av kollegors etiska övertramp mot elever och svårigheten att ingripa till elevernas försvar. De av lärarna beskrivna händelserna gäller olika exempel på kollegors maktmissbruk, såsom aggressivt ledarskap, sårande yttranden och orättvis behandling. Lärarna som rapporterade sådana händelser resonerade också om sin oförmåga att ingripa. De hade dåligt samvete över att de inte hade agerat för att skydda eleverna. Flera skäl till att de förblev passiva framkom, och de hade inte intervenerat trots att kollegans beteende hade upprepats år efter år. De hänvisade till svårigheten att påta sig rollen som den som bäst vet hur en lärare bör handla och påpekade att det endast var deras subjektiva uppfattning om hur lärare bör behandla eleverna som låg till grund för deras bedömning och eventuella ingripande. De kan sägas ha saknat gemensam uppfattning om vad som är acceptabelt, rimligt och önskvärt i lärares bemötande av elever. Ohnstad (2008) kom till liknande resultat av norska lärares etiska dilemman. 
Lärarna hänvisade också till andra skäl för att inte ingripa, av mera socialpsykologisk karaktär. Att ta på sig rollen som kritiker inom en grupp av kollegor innebär sociala risker. Man kan riskera att själv bli kritiserad och som en lärare uttrycker det:

När jag starkt misstänker att en kollega handlar fel mot eleverna. Hur ska jag göra? Hur mycket energi har jag? Kommer jag att stå ensam?

Risken att förlora sin plats i samfälligheten, som Nussbaum (1995) uttrycker det, är inte obetydlig. De sociala processer som uppstår vid de moraliska handlingar som kallas whistle-blowing är verkliga hot mot individen. Bok (1988) utvecklar idrottsmetaforen ytterligare; om den som blåser i visselpipan varken är domare, lagledare eller tränare saknas mandat att ingripa. Så är fallet i relationen mellan lärarkollegor.

Ovanstående studie replikerades drygt tio år senare och när det gäller detta etiska dilemma är resultaten påfallande lika, trots att svenska lärare fick etiska riktlinjer 2001. Jag återkommer senare till detta.

\section{Läraryrkets professionalisering}

Den ökande medvetenheten om lärares moraliska ansvar för hur makten utövas var således den ena ingången till intresset för yrkesetik i lärarprofessionen. En annan ingång var en önskan att höja läraryrkets status i samhället. Professionaliseringsprocessen drevs av såväl lärarnas två fackförbund som av utbildningspolitiker, men på olika sätt och utifrån olika motiv.

Fackförbunden (Lärarförbundet och Lärarnas riksförbund) jämförde läraryrket med etablerade professioners utmärkande drag. De kännetecken som vanligtvis brukar nämnas i professionsteorier (t.ex. Etzioni 1969) är

- gemensam vetenskaplig kunskapsbas och gemensamt yrkesspråk

- yrkesmässig autonomi

- statlig auktorisation/legitimation

- egenkontrollerad yrkesetik (professionen övervakar sina medlemmars etiska handlande).

Lärarnas organisationer lade upp en långsiktig plan för att påverka läraryrket i riktning mot dessa professionella kännetecken i avsikt att stärka läraryrkets ställning i samhället. De räknade med att ha frihet att driva sin professionalisering, eftersom utbildningspolitiken under samma period gick mot decentralisering, avreglering och målstyrning i stället för regelstyrning. Den läroplan som blev gällande 1994 innehöll exempelvis endast övergripande mål och skulle inte vara större än att den rymdes i en bakficka eller handväska, enligt dåvarande utbildningsminister. Utbildningspolitikerna gav uttryck för uppfattningen att lärarna var professionella och att de själva kunde utforma undervisningen i riktning mot målen, utan detaljerad styrning. 
Denna snabba omsvängning har beskrivits som en "chockprofessionalisering", eftersom det saknades förberedelser för lärarnas plötsligt utökade autonomi och ansvar. De politiska motiven var inte endast ädla; staten ansåg att skolan var en alltför dyr institution och ville att kommunerna skulle ta över ansvaret för kostnaderna. Det som följde var inte decentralisering till lärarna, utan makten gick till de lokala skolpolitikerna. Det fria skolvalet och friskolereformen förväntades öka konkurrensen mellan skolor, vilket i sin tur också skulle höja kvaliteten. Eftersom politikerna inte beslutade om några begränsningar vad gäller vinstuttag ur friskolorna fick även den reformen helt andra och oönskade konsekvenser. När skolan blev en marknad berövades lärarna en del av sitt professionella handlingsutrymme, eftersom elever och föräldrar blev kunder som man inte ville förlora till konkurrenterna.

\section{Lärares yrkesetiska principer}

Frågan om en för lärare gemensam yrkesetik bearbetades i ett mer rimligt tempo av de båda fackliga lärarorganisationerna och kunde efter fem års diskussioner, seminarier och försök till förankring leda fram till de tidigare nämnda etiska riktlinjerna år 2001. De etiska riktlinjer som lärarnas organisationer i samarbete utarbetade berör centrala områden inom lärares yrkesutövning. De innehåller i likhet med de flesta yrkesetiska regelverk principer för vad som är professionens höga mål, portalparagrafer, som anger det goda man vill bidra med i samhällets tjänst. Det gäller bland annat att ta ansvar för elevernas kunskapstillväxt, bemöta eleverna med respekt för deras person och integritet, inte diskriminera någon och upprätthålla förtroendefulla relationer. De etiska riktlinjerna innehåller också de restriktioner som professionen ålägger sig själv för att inte överutnyttja sin makt i den asymmetriska relationen, det som kan kallas det onda man inte vill göra. Denna ambition visar sig i termer av att lärare förväntas ingripa om en kollega begår övertramp och är formulerad på följande sätt:

Lärare visar god kollegialitet men inte på ett sådant sätt att det kan leda till handling eller underlåtenhet som kan skada eleverna. Lärare ingriper om en kollega uppträder kränkande mot en elev eller motverkar en elevs rättigheter (Lärares yrkesetiska principer 2001).

Som framgår har lärarna fastställt en lägsta gräns för vad som är ett acceptabelt sätt att bemöta elever, även om texten kräver tolkning. Riktlinjerna fastslår en moralisk skyldighet att ingripa till elevers försvar om en kollega bryter mot yrkesetiken och behandlar en elev skadligt eller kränkande.

När dessa principer beslutades och började gälla kunde man förvänta sig att det skulle bli lättare för lärare att ingripa mot kollegor som behandlar elever illa. Lärarna i den studie som genomfördes på 1990-talet hade inte haft något annat än sitt eget omdöme och sina privata moraliska normer att hänvisa till när de bedömde kollegornas handlingar som skadliga och moraliskt klandervärda. Efter principernas tillkomst hade de fått tillgång till etiska principer som referens när de ifrågasatte en kollegas sätt att behandla eleverna. 
En uppföljande studie med samma design och metod som den ovan refererade kunde genomföras under åren 2008-2010 med hjälp av medel från Forskningsrådet för arbetsliv och samhälle (FAS, numera Forte). Denna studie genomfördes med samma metod (CI) som den tidigare: lärare beskrev med egna ord situationer som de uppfattat som etiskt eller moraliskt svåra i sin vardagliga praktik. Efter analys av de kritiska händelser som lärarna rapporterade framkom att den mest frekventa kategorin handlar just om kollegor som behandlar eleverna på ett etiskt klandervärt sätt. I den senare studien, som genomfördes under åren 2008-2010, framstår således fortfarande svårigheten att ingripa mot en kollega som behandlar eleverna illa som en svår moralisk utmaning (Colnerud 2014a).

Om de etiska principerna vore reellt förankrade och hade utgjort det stöd för lärares moraliska handlingsval som de är avsedda att vara, så skulle lärarna ha kunnat hänvisa till den ovan citerade principen och handla därefter. Ingen av de lärare som beskriver sin svårighet att ingripa mot en kollega till elevernas försvar nämner de etiska riktlinjernas existens, och lärarnas resonemang avslöjar inte att de känner till det krav på ingripande som riktas till varje lärare. Principerna utgör således varken en uppmaning till eller stöd för den handling som de aktuella lärarna anser vara etiskt riktig men svår att genomföra.

Även i denna uppföljande studie hänvisar lärarna till de sociala risker som följer av att bryta mot den kollegiala lojaliteten. De tvekar inför att konfrontera kollegan med den kritik som deras invändningar innebär.

Det svåraste är att kritisera en kollega som behandlar eleverna på ett sätt som man tycker är fel. Om man inte säger något känner man sig dålig och om man påpekar det för kollegan måste man göra det på ett sätt som gör det möjligt att acceptera.

De uttrycker en önskan att skydda kollegan mot den skada som kritik kan medföra. Att som lärare behandla eleverna illa kan tolkas som ett uttryck för misslyckande, otillfredsställelse och kanske till och med vanmakt. En lärare, som vill skydda sin kollega, frågar sig hur denna kommer att reagera på hennes kritik.

Jag tycker det är svårt att agera när elever kommer med allvarlig kritik om en kollega ../.. Hur ska jag prata med min kollega utan att såra henne?

Att ta hänsyn till kollegans sårbarhet är både rimligt och etiskt försvarbart. Den försiktighet som läraren uttrycker leder emellertid till en passivitet som kan riskera elevernas välbefinnande.

Som tidigare nämnts föregicks beslutet om de etiska principerna av seminarier och öppna diskussioner under flera år. Lärarförbunden gav ut diskussionsunderlag med fallbeskrivningar av etiska dilemman, vilka utgjorde utgångspunkt för samtal mellan lärarna som deltog. Lärarna i Sverige är emellertid en till antalet ovanligt stor yrkesgrupp, över 200 000. Den förberedande diskussionen nådde givetvis inte alla. Dessvärre avstannade dessutom samtalet om yrkesetiska frågor när beslutet om de etiska principerna var fattat. Först efter några år riktades återigen uppmärksamheten mot yrkesetiken genom olika texter, bland annat en antologi (Nordenfalk 2004) och ett temanummer av tidskriften Pedagogiska Magasinet (2004). 


\section{Etiska principer som vägledning eller hinder för professionellt omdöme}

Etiska principers möjlighet att utgöra vägledning för professionellas handlande har ifrågasatts. Vid tiden för arbetet med att utveckla och formulera de svenska lärarnas yrkesetik framställdes etiska regelverk som motstridiga utvecklingen av eget omdöme. Den ståndpunkten utgick från dygdetiker som vilar på Aristoteles etik (t.ex. McIntyre 1984), vilka menade att etiska principer kan hindra oss från att utveckla vårt eget etiska omdöme och det praktiska förnuftet som Aristoteles benämnde phronesis (Colnerud 2001). Phronesis är den dygd som gör det möjligt för individen att hitta rätt handling i varje enskild situation, vilket kräver erfarenhet och tid.

Aristoteles argumenterade mot systematiskt bruk av regler och menade att man inte mekaniskt kan finna rätt handlingsval. Men han gör, vilket inte är så välkänt, undantag för vissa omständigheter då generella riktlinjer kan vara ändamålsenliga. Det finns, enligt Aristoteles, tre skäl till att etiska riktlinjer kan vara användbara:

- Om det inte finns tid till att formulera ett helt konkret beslut i ett givet fall är det bättre att följa en sammanfattande regel eller en standardiserad beslutsprocess än att träffa ett förhastat och inadekvat kontextuellt handlingsval.

- Om det finns skäl att tro att partiskhet eller specifika intressen kan förvränga vårt enskilda omdöme, då ger oss regler återigen varaktighet och stabilitet.

- Regler och generella procedurer kan vara hjälpmedel i den moraliska utvecklingen eftersom människor som ännu inte besitter den praktiska visheten och insikten behöver följa regler som är sammanfattningar av andras kloka omdömen. (Nussbaum 1995: 71-72).

Motsättningen mellan dygd och principer kan således betraktas som falsk i de fall som framkommer i Nussbaums tolkning av Aristoteles. Principer kan behövas även om de inte bör användas mekaniskt eller ersätta strävan efter visheten.

Om vi studerar den etiska princip som säger att lärare ska ingripa om en kollega uppträder kränkande eller motverkar en elevs rättigheter, kan vi se att den främst skulle uppfylla den andra förutsättningen ovan: läraren som inte förmår ingripa till skydd för eleven och därmed frångå normen om kollegial lojalitet, visar partiskhet och tar hänsyn till specifika intressen, dvs. kollegans - och även sina egna. Principen att ingripa skulle, om den vore känd och om den uppfattas som legitim, kunna hjälpa kollegan att handla utifrån elevens intresse, dvs. ingripa till elevens försvar.

Lärarna i de två empiriska studierna visar sig emellertid inte vara hjälpta att välja den handling som de själva anser vara den rätta. Varken dygd eller principer tycks vara tillräckliga för att övervinna de svårigheter som det innebär att bryta mot den kollegiala lojalitetsnormen och övervinna rädslan för att bli exkluderad ur gemenskapen.

Regler skulle enligt den ovan nämnda dygdetiska kritiken förhindra att lärare utvecklar sin praktiska vishet och därmed komma fram till den rätta handlingen. De kommer förvisso fram till vad som är rätt handling, men deras problem är att de inte kan förmå sig 
till att utföra den. Om de hade utvecklat phronesis skulle de ha agerat. Vi vet inte om de hade fått stöd i den etiska principen om den hade varit känd, vilket den troligen inte var.

\section{Juridifiering}

De yrkesetiska principerna utgör emellertid inte det största hotet mot utvecklingen av dygder. I Sverige, liksom i många andra länder, pågår en juridifiering av skolans normer. Förvaltningsstyrning, den styrning som politiker utövar över professioners yrkesutövande, sker genom lagar och förordningar. Den skiljer sig från professionsstyrning som vilar på utbildning, vetenskap och etik. Om professionsstyrning råder genomför de professionella sina uppgifter och löser problem utifrån arbetets övergripande samhällsuppgift och innehåll med stöd av sin kompetens och yrkesetik (Svensson 2011; Colnerud 2014b). Som kontrast till den tidigare nämnda chockprofessionaliseringen kan man säga att förvaltningsstyrningen har medfört en chockreglering under de senaste åren.

Skollagen reglerar numera många mellanmänskliga förhållanden som tidigare ansågs vara pedagogiska. Juridifiering kan beteckna flera fenomen. I vid mening innebär det att allt fler företeelser införlivas i det juridiska paradigmet. Företeelser som tidigare inte har varit normerade av lagar blir lagreglerade (Brännström 2011). Moraliska frågor transformeras till juridiska frågor och rättsliga processer, och rättsliga instanser såsom domstolar antas kunna lösa problem och konflikter som andra professioner inte har lyckats lösa (Colnerud 2014b). Forskare inom juridik benämner ibland fenomenet "förrättsligande" (t.ex. Brännström 2011). På engelska skrivs begreppet oftast "juridification" (Blichner \& Molander 2005).

I det fall som vi här undersöker betyder det att lärare numera är skyldiga att anmäla kollegor som behandlar elever kränkande. Ingripande av kollega eller kritik kollegor emellan är överspelat. Nu måste läraren anmäla kollegan till rektor för vidare anmälan till kommunen. I skollagens kapitel 6 kan vi läsa:

$10 \S$ En lärare, förskollärare eller annan personal som får kännedom om att ett barn eller en elev anser sig ha blivit utsatt för kränkande behandling i samband med verksamheten är skyldig att anmäla detta till förskolechefen eller rektorn. En förskolechef eller rektor som får kännedom om att ett barn eller en elev anser sig ha blivit utsatt för kränkande behandling i samband med verksamheten är skyldig att anmäla detta till huvudmannen. Huvudmannen är skyldig att skyndsamt utreda omständigheterna kring de uppgivna kränkningarna och i förekommande fall vidta de åtgärder som skäligen kan krävas för att förhindra kränkande behandling i framtiden.

Första stycket första och andra meningarna ska tillämpas på motsvarande sätt om ett barn eller en elev anser sig ha blivit utsatt för trakasserier eller sexuella trakasserier på sätt som avses i diskrimineringslagen. (Skollagen 2008: 567)

Problemet flyttas bort från professionen till ledningen för skola och kommunen, som kan bli skyldig att betala skadestånd till eleven.

$12 \S$ Om huvudmannen eller personalen åsidosätter sina skyldigheter enligt 7, 8, 9, 10 eller $11 \S$ ska huvudmannen dels betala skadestånd till barnet eller eleven för den kränkning som detta innebär, 
dels ersätta annan skada som har orsakats av åsidosättandet. Skadestånd för kränkning i andra fall än vid repressalier lämnas dock inte, om kränkningen är ringa.

Det betyder att frågan om vad som har hänt, varför det har hänt och om det är frågan om en kränkning eller ej avgörs av jurister. Lärarprofessionen äger inte längre frågan om att korrigera kollegor som behandlar eleverna illa. Den har flyttat ut ur skolan till juridiska instanser.

\section{Diskussion}

Lärarnas yrkesetiska principer kom att gälla i sex år innan den nuvarande skollagen trädde i kraft. Vi kommer inte att få veta om professionen så småningom hade utvecklat sitt yrkesetiska ansvarstagande med stöd av principerna. Vi vet inte heller om anmälningsskyldigheten kommer att medföra att flera lärare anmäls av kollegor, men det står klart att anmälningar från elever och föräldrar stadigt ökar. En del av dessa är säkert berättigade. Möjligheten att en elev kan tilldömas skadestånd har emellertid också lockat föräldrar att anmäla lärare för handlingar som kan anses ingå i lärarens uppdrag, t.ex. att korrigera en elevs beteende när denne stör undervisningen. Lärare beskriver att de drabbats av vad de kallar för anmälningsrädsla, en oro för att bli anmäld för kränkande behandling. Även om kränkningen befinns vara ringa, eller ingen kränkning alls, är det en obehaglig och stressande situation att bli föremål för rättslig prövning. Denna rädsla får även pedagogiska konsekvenser som vi emellertid inte behandlar här.

En fråga man måste ställa sig är om det inte är bra att eleverna får ett ökat rättsskydd mot de lärarhandlingar som är kränkande eller skadliga. Förvisso är det viktigt att elever inte utsätts för dålig behandling, men frågan är om man på juridisk väg uppnår en förändring till en medvetenhet om lärarens etiska ansvar. Om alla lärare mer eller mindre delar rädslan för att bli anmälda och granskade av juridisk instans kan man tänka sig att de också utvecklar rädsla för att anmäla varandra.

Sett ur professionens synvinkel är denna utveckling en förlust av autonomi och av möjligheten att upprätthålla eller höja sitt anseende i samhället. Om professionen hade visat att man inte skyddar de kollegor som begår yrkesetiska övertramp, utan att man i stället har försökt påverka deras handlande i riktning mot det etiskt önskvärda, så hade förtroendet för lärarna kunnat öka.

Yrkesetiken uppmanar till att ingripa, skollagen kräver att man anmäler. Dessa handlingar utmanar olika moraliska kvaliteter. Ett ingripande sker i närhet och i direkt kontakt med kollegan. Handlingen kräver mod och övertygelse om att ett ingripande är moraliskt nödvändigt och att en förändring måste ske. Det innebär, som visats ovan, sociala risker.

En anmälan däremot följer ett juridiskt imperativ: man är skyldig att anmäla. Därefter tas frågan om hand av andra. Följderna för den anmälda kan bli stora, eftersom rättsfall uppmärksammas av media. Viljan att skydda kollegan kan väntas öka, varför vi kan anta att lärare kommer att avstå från att anmäla om övertrampen inte är extraordinära. I sådana fall har troligen elever och föräldrar redan reagerat. 
Yrkesetiken måste få kraft bakom sig för att fungera så att den skyddar eleverna och minskar de sociala riskerna. Juridiken har mycket makt bakom sig och vi har ännu inte sett vad den innebär för hur lärare tar sitt etiska ansvar för eleverna.

\section{Litteratur}

Aristoteles (300-talet B.C. [1955]) The nichomachean ethics. London: Penguin Classics.

Bergem, T. (1993) Tjener - aldri herre. Om loererutdanning og yrkesetiske holdninger. Stavanger: NLA-forlaget.

Blichner, L. C. \& Molander, A. (2005) What is juridification? Oslo: Centre for European Studies.

Brännström, L. (2011) Förrättsligande genom konstitutionalisering och parlamentarismens slut. I: Förrättsligande. Rapport från 2011 års forskningsinternat. Umeå: Juridiska institutionen, Umeå universitet.

Colnerud, G. (1995) Etik och praktik i läraryrket. Stockholm: HLS förlag.

Colnerud, G. (1997) Ethical conflicts in teaching. Teaching and Teacher Education, 6, s. 627-636.

Colnerud, G. (2001) Aristotle and teacher ethics. Nordic Studies in Education, 21, s. 149-156.

Colnerud, G. (2014a) Moral stress in teaching practice. Teachers and Teaching: Theory and Practice, in press.

Colnerud, G. (2014b) Skolans juridifiering - Om styrning av lärarprofessionen. Skola och samhälle, (2), s. 2.

Eriksson, B. E. \& Larsson, T. (1974) Lärarnas upplevelse av skolarbetet. Skolan som arbetsplats. Rapport från Utredningen om skolans inre arbete - SIA. Utbildningsdepartementet.

Etzioni, A. (1969) The semi-professions and their organizations. New York: The Free Press.

Goodlad, J., Soder, R. \& Sirotnik, K. (1990) The moral dimensions of teaching. San Fransisco: Jossey Bass Inc. Publishers.

Flanagan, J. C. (1954) The critical incident technique. Psychological Bulletin, 51, 237-258.

Lärarnas riksförbund. http://www.lr.se/duidinyrkesroll/yrkesetik/lararesyrkesetiskaprinciper.

Nordenfalk, K. (red.) (2004) Etik i princip och praktik. Stockholm: Lärarförbundet \& Lärarnas Riksförbund.

McIntyre, A. (1984) After Virtue. Notre Dame, Indiana: University of Notre Dame Press.

Nussbaum, M. (1992) Vana, passion och reflektion i den aristoteliska traditionen. Divan, 5, s. 7482.

Nussbaum, M. (1995) Känslans skärpa, tankens inlevelse. Essäer om etik och politik. Stockholm: Brutus Östlings Bokförlag Symposion.

Ohnstad, F. O. (2008) Profesjonsetiske dilemmaer og handlingsvalg blant loerere i loererutdanningens praksisskoler. Oslo: Unipub.

Pedagogiska Magasinet (2004) (4).

Skollagen (2010:800) Stockholm: Nordstedts juridik.

Svensson, L. (2011) Profession, organisation, kollegialitet och ansvar. Socialvetenskaplig tidskrift, 18 (4), s. 301-319.

Tom, A. (1984) Teaching as a moral craft. New York: Longman. 